ISSN 1409 - 469X

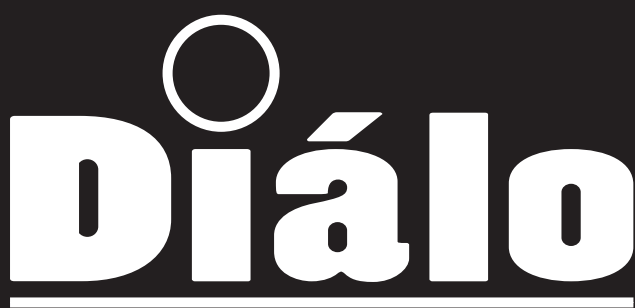

url: http://revistas.ucr.ac.cr/index.php/dialogos/index

\title{
Revista Electrónica de Historia
}

\section{Escuela de Historia. Universidad de Costa Rica} Vol. 16 No. 2 julio-diciembre 2015
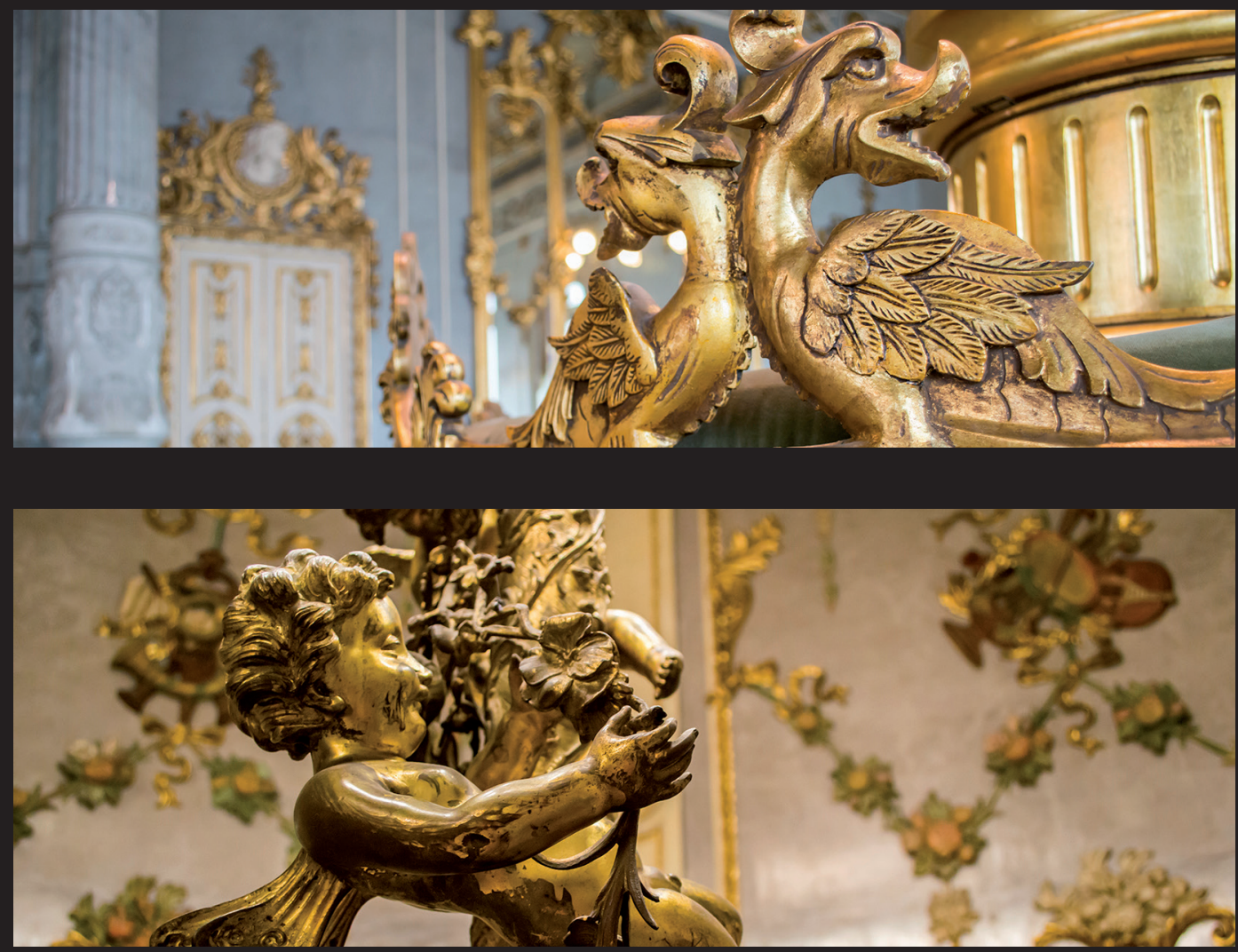

Director de la Revista: Dr. Juan José Marín Hernández juan.marinhernandez@ucr.ac.cr

Editor académico: Dr. David Díaz Arias - david.diaz@ucr.ac.cr Editor técnico: M.Sc. Marcela Quirós G. - marcela.quiros@ucr.ac.cr 


\title{
LOS DISCURSOS DE LA COCINA NACIONAL COSTARRICENSE Y LA REUBICACIÓN CULTURAL DE GUANACASTE
}

\author{
DISCOURSES ON THE COSTA RICAN NATIONAL CUISINE AND THE CULTURAL \\ RELOCATING OF GUANACASTE
}

Mona Nikolić*

\begin{abstract}
Palabras claves
Cocina nacional, hábitos alimenticios, identidad de resistencia, pertenencia cultural, transnacionalización.
\end{abstract}

\section{Keywords}

National Cuisine, eating habits, resistance identity, cultural belonging, transnationalization.

Fecha de recepción: 15 de mayo de 2014 - Fecha de aceptación: 6 de noviembre de 2014

\begin{abstract}
Resumen
Durante los últimos años, frente a la creciente transnacionalización del consumo, el tema de la cocina nacional ganó cada vez más importancia en Costa Rica. Además de manifestar la importancia de la cocina nacional como marcador de identidad, estos discursos dan cuenta de la renegociación de diferencias culturales y regionales que ocurre en el actual contexto de la formación de la cocina nacional costarricense. Respecto a la formación de una cocina nacional, el impacto de esta construcción en las diferentes cocinas regionales y étnicas es un tema relevante. Por la marginalización de las regiones de Guanacaste y Limón y sus habitantes en los discursos de nacionalidad costarricense del pasado, es interesante examinar las cocinas de estas provincias. Este artículo trata la discusión local del concepto de la cocina nacional costarricense. Recurriendo a los resultados de mi trabajo de campo en Guanacaste en 2011, mostraré que la construcción de una cocina nacional va acompañada con el aumento en importancia de la cocina local como marcador de identidad regional. Argumento que se puede entender a la identidad guanacasteca expresada en esta discusión como identidad de resistencia y que la discusión motiva una renegociación de pertenencia regional, nacional y cultural.
\end{abstract}

\begin{abstract}
In recent years, due to the growing transnationalization of consumption, national cuisine has been given ever more consideration in Costa Rica. Apart from making explicit the relevance of the national cuisine as a marker of national identity, the national cuisine's discussion gives proof of the renegotiation of cultural and regional differences taking place in the current context of this cuisine's formation. Studying the formation of a national cuisine, it is relevant to consider its impact on regional and ethnic cuisines. For the marginalization of the provinces of Guanacaste and Limón and their habitants in the discourses on Costa Rican national identity in the past, it is particularly interesting to contemplate these regional cuisines.This article focuses on the way the current concept of a Costa Rican National Cuisine is discussed on a local level, in Guanacaste. Drawing on results of my fieldwork conducted in 2011, I will show that the construction of a national cuisine is accompanied by a rise of the local cuisine's importance as a marker of regional identity. I hold that Guanacastecan identity, as expressed in this discussion can be understood as resistance identity and that the discussion motivates a renegotiation of regional, national and cultural belonging.
\end{abstract}




\section{INTRODUCCIÓN}

En su artículo "Metáforas de la cocina”, Marjorie Ross González (2008), pionera en la investigación de la cocina costarricense, resumiendo sus esfuerzos para rescatar las recetas de la cocina tradicional de Costa Rica, comenta la incomprensión para la relevancia de su trabajo entre la población costarricense en la década de los ochenta (p. 11). En esta década y la siguiente, aparte de unos trabajos de rescate ${ }^{1}$ en el campo de las ciencias sociales, fue sobre todo por parte de los historiadores que se dio consideración al tema del consumo y de la relación entre hábitos de consumo e identidades en Costa Rica. ${ }^{2}$

Durante los últimos años, sin embargo, frente a la creciente transnacionalización del consumo, el tema de la cocina nacional costarricense ocupó un espacio cada vez más importante en Costa Rica. ${ }^{3}$ En el centro de los discursos actuales de cocina nacional costarricense, tanto en el ámbito académico como en el público, está el miedo de perder la propia cocina, y junto a esta, la salud, así como la cultura e identidad. Además de manifestar la importancia de la cocina nacional como marcador de identidad nacional, los discursos contemporáneos dan cuenta de la renegociación de diferencias culturales y regionales que ocurre en el actual contexto de formación y tematización de la cocina nacional costarricense.

En este artículo, trataré la relación entre la construcción de la cocina nacional costarricense y las cocinas regionales, enfocándome en la cocina guanacasteca. Expondré la negociación local del concepto de la cocina nacional y las imágenes de la cocina y cultura guanacastecas presentes en los discursos de la cocina nacional. Por la relevancia de la imagen de la "cultura del maíz" mesoamericana en la discusión local, me concentraré en este aspecto de la cultura e identidad guanacastecas. ${ }^{4}$ Argumento que la formación de una cocina nacional va acompañada de un aumento en la importancia de la cocina local como marcador de identidad regional. Mostraré que el debate local de la cocina nacional está afectado por la marginalización histórica de los guanacastecos y que se puede entender a la identidad guanacasteca expresada en esta discusión como identidad de resistencia; así mismo, señalaré que esta discusión motiva la renegociación de la relación de Guanacaste con Costa Rica y Nicaragua, o sea, una reubicación y renegociación de pertenencia nacional, regional y cultural.

Antes de entrar en la discusión de los discursos de cocina y de identidad nacional costarricense, expondré a grandes rasgos el proceder metódico. 


\section{EL PROCEDER METÓDICO}

Los resultados que presentaré aquí forman parte de las investigaciones que realicé para mi tesis doctoral, tratando el tema del impacto de la globalización cultural en los hábitos alimenticios y la cocina nacional costarricense. El proceder metódico consiste en una combinación de un análisis de publicaciones académicas sobre el tema de la cocina nacional costarricense y el trabajo de campo. Mi investigación de la construcción de la cocina nacional se basa en las representaciones de esta cocina en recientes publicaciones académicas, originadas con el fin de conservar la cocina nacional como parte del patrimonio cultural costarricense. En este artículo me enfocaré principalmente en los trabajos de Marjorie Ross González (2001), Giselle Chang Vargas (2001), Patricia Sedó Masís (2008a, 2008b) y la recopilación de recetas de cocina tradicional costarricense publicada por Yanori Álvarez Masís (2005). En el trabajo de campo, investigué la importancia de la cocina local como marcador de identidad y su construcción bajo la negociación de las imágenes presentes en los discursos académicos y públicos de la cocina nacional, así como bajo la negociación de relaciones transnacionales. La recopilación de datos se basó en técnicas cualitativas de investigación, especialmente en la combinación de la observación participante y las entrevistas cualitativas de manera semi-estructurada, complementadas por las técnicas del Free-Listing y del Pile Sorting. Los resultados presentados aquí provienen de la parte del trabajo de campo que realicé en la ciudad de Santa Cruz de Guanacaste de junio hasta agosto de 2011.

\section{SANTA CRUZ DE GUANACASTE}

La ciudad de Santa Cruz, cabecera del cantón del mismo nombre, está ubicada en el centro de la península de Nicoya. El cantón de Santa Cruz, según datos del último censo cuenta con una población de 21544 habitantes (Instituto Nacional de Estadística y Censos, 2011). Santa Cruz, además de tener una historia precolombina bien documentada - pertenece a la región arqueológica de la Gran Nicoya - y un rol central en la historia de la Anexión de Guanacaste a Costa Rica (Cabrera, 1989, pp. 41-42, 2007, p. 484; Leal, 1998, pp. 71, 82), desempeña un papel importante en los discursos de cultura nacional costarricense, por ser la ciudad declarada "Ciudad Folclórica Nacional de Costa Rica". Con respecto a mi tema de investigación, la cocina tradicional, hay que mencionar que la ciudad de Santa Cruz hoy día es famosa por sus tradiciones culinarias (Morales, 2009, p. 36) y la conservación de estas. En Santa Cruz trabajé con 15 informantes principales y sus familias, entre ellos personas especializadas en la producción y la venta de comidas típicas 
y populares, como cocineras en las sodas locales o en las fiestas cívicas, así como con amas de casa, maestros y artesanos, todos ellos personas que en su mayoría estaban preocupadas por la conservación de la cultura culinaria local e interesadas en la historia precolombina costarricense.

Antes de entrar en la discusión de los discursos de cocina nacional costarricense y el manejo de las diferencias intranacionales, por la relevancia de imágenes históricas y actuales de la identidad nacional costarricense en estos discursos, en la siguiente sección describiré brevemente los discursos históricos y contemporáneos de la identidad nacional costarricense.

\section{LOS DISCURSOS DE IDENTIDAD NACIONAL COSTARRICENSE}

La identidad costarricense construida en el contexto de la formación de la nación costarricense al final del siglo XIX se basaba en la imagen de una nación blanca, homogénea, pacífica, democrática y campesina (Chacón, 2000, pp. 84-85; Molina, 2008, pp. 20, 37; Molina y Palmer, 2009, pp. 72-73, 92; Sandoval, 2004, pp. XV-XVI, 62, 67). Esta imagen recalcaba la singularidad de la nación costarricense en el contexto regional mesoamericano - como la nación más europeay la diferenciaba de las demás naciones mesoamericanas, siendo particularmente importante la distinción frente a Nicaragua. La población nicaragüense, como señala Carlos Sandoval García, en los discursos de identidad nacional costarricense era encasillada en el papel del "otro", atribuyéndosele todos los antivalores costarricenses (Sandoval, 2004, pp. 89, 94, 109, 157, 160, 174).

Es por la primacía dada a la característica de la blanquitud en particular que esta construcción a la vez de excluir "otros externos" también creó "otros internos" y limitó a la nación costarricense a la población del Valle Central. Eso se debía al hecho de que los grupos que no correspondieron a la característica de blanquitud, y por ello eran marginados y excluidos del discurso de nacionalidad costarricense, en su mayoría vivieron fuera de la Región Central (Molina, 2008, pp. 19-22). Entre ellos se encontraban los grupos indígenas costarricenses así como los afrocaribeños, habitantes de la provincia de Limón, pero también los habitantes de la provincia de Guanacaste. Los guanacastecos eran marginados por dos razones vinculadas: primero, por haber estado alternativamente bajo la Intendencia de León y Granada antes de la anexión a Costa Rica en 1824, la región de Guanacaste era ampliamente percibida como nicaragüense; segundo, la población guanacasteca, por su procedencia de un país mesoamericano y la predominancia de la cultura autóctona mesoamericana en la región, era considerada como "más indígena" que la población costarricense, o sea la población del Valle Central. Por estas dos razones, los 
guanacastecos eran tratados con menosprecio (Cabrera, 1989, p. 13; Chacón, 2000, p. 84; Molina, 2008, p. 21).

Los discursos de la nacionalidad costarricense no solamente revelan la importancia del 'otro' en el proceso activo de construcción de identidades (Cornell y Hartmann, 2007, p. 84), sino también subrayan que la construcción de identidades siempre ocurre y está intercalada en un contexto de relaciones de poder. Tomando en cuenta este contexto de poder, Manuel Castells (2004) distingue entre tres formas y orígenes de identidades colectivas: la identidad legitimadora, la identidad de resistencia y la identidad de proyecto. Entre estas, la identidad legitimadora es la identidad originada por instituciones dominantes para asegurar el statu quo y, según Castells, es la forma de identidad que a menudo se encuentra en los discursos de identidad nacional. Por otro lado, la identidad de resistencia es establecida por actores sociales marginados a base de identidades históricas, geográficas, etc., para construir formas de resistencia colectiva (2004, pp. 8-9). En los discursos históricos de la identidad nacional costarricense tenemos tanto un concepto de identidad legitimadora que excluyó a gran parte de la población costarricense como también identidades adscritas a los actores sociales marginados que en la actualidad pueden formar la base de identidades de resistencia. Por lo tanto, tomo los conceptos de identidad legitimadora e identidad de resistencia como conceptos aplicables al contexto costarricense. Hablando de la marginación de grupos sociales y culturales en los discursos de la identidad nacional costarricense, además es interesante considerar los cambios que se dieron en los conceptos institucionales de identidad nacional a partir de los años ochenta.

A partir de la década de los ochenta se reconoció políticamente a las múltiples raíces étnicas y culturales de la sociedad costarricense. En vez de dar primacía a los aportes culturales europeos, en los nuevos conceptos de identidad nacional costarricense, las influencias autóctonas, asiáticas y africanas son igualmente tomadas en consideración (Molina, 2008, pp. 111-112), y la imagen de la sociedad culturalmente homogénea es reemplazada por la de una sociedad diversa, aun igualitaria (Molina, 2008, pp. 112-113; Sandoval, 2004, p. 109). Es un concepto de identidad nacional costarricense que está incluyendo a los actores sociales y culturales anteriormente excluidos y que acepta la heterogeneidad cultural y regional de la nación. Este concepto de la identidad nacional incluyente permite la existencia de identidades regionales y sociales, pero en vez de excluirlas, las integra al concepto de identidad nacional. Sin embargo, es importante recordar que, como dice Castells (2004, p. 7), aunque los conceptos de identidades pueden ser originados por instituciones, es solamente por la identificación de los actores sociales con estas imágenes externas que se convierten en identidades. Por lo tanto, es interesante investigar la discusión de estos conceptos institucionales a nivel local. En este artículo, investigaré 
la negociación de pertenencia cultural y nacional, a través de la discusión local de los conceptos institucionales de la cocina nacional y las cocinas regionales como marcadores de identidades.

\section{LA PRESENTACIÓN DE LA COCINA NACIONAL COSTARRICENSE EN LOS DISCURSOS ACADÉMICOS}

La cocina, como subraya Eva Barlösius (1999), es un código cultural complejo, que contiene instrucciones para el sabor, la combinación de ingredientes y la manera de prepararlos, así como la forma y la ocasión para comerlos (p. 123). Al garantizar la uniformidad del sabor, estas reglas, según Barlösius (1999), hacen que la cocina, de manera más explícita que otros productos culturales, transmita sentimientos de pertenencia o extrañeza y por ello sirve tanto para unir como para separar comunidades (pp. 123-124).

Puede entenderse a las cocinas nacionales entonces como marcadores fundamentales de identidades nacionales. Por lo tanto, su construcción y conservación es un elemento importante en el proceso de formación o conservación de una nación en el contexto de la globalización (Barlösius, 1999, pp. 147-148). En Costa Rica, el interés tanto académico como político y público en el rescate de las recetas de la cocina nacional costarricense, subraya la importancia de la cocina como marcador de la identidad nacional en el periodo de la globalización cultural. Además de dar cuenta de la relevancia otorgada al rescate de la cocina nacional, la actual recopilación de recetas tradicionales también toma un papel central en la construcción del mismo concepto de la cocina nacional costarricense como marcador de identidad. Como han argumentado varios autores, entre ellos Arjun Appadurai (2008) y Priscilla Parkhurst Ferguson (2010), con la selección de algunas recetas y su incorporación en los libros de una cocina nacional, se define qué comidas y maneras de preparación son características de esa cocina nacional. Por ello, los libros de cocina sirven como referencia y autoridad sobre sabores, modos de preparación, platos y bebidas pertenecientes a la cocina nacional (Parkhurst, 2010, p. 102; Sutton, 2001, p. 142). Este proceso de construcción de cocinas nacionales por lo general es dominado por una ideología integracionista, es decir, las diferentes culturas culinarias étnicas y regionales son ignoradas, ocultando así las diferencias regionales y étnicas que existen dentro de la nación (Appadurai, 2008, p. 304; Ayora-Diaz, 2010, p. 400).

Los procesos de construcción de identidad y cocina entonces muchas veces se llevan a cabo de la misma forma y una revisión de las recopilaciones 
de recetas tradicionales costarricenses da cuenta de la congruencia entre el concepto actual de la cocina y de la identidad nacional costarricense.

En los discursos actuales, tanto en el ámbito académico como en el público, la cocina nacional costarricense es definida como cocina criolla costarricense, es decir, como una cocina resultante de la confluencia de diferentes y distintas tradiciones culinarias, entre las cuales destacan la cultura culinaria europea-española, la autóctona americana y la afrocaribeña (Álvarez, 2005, p. 45; Ross, 2001, p. 32; Sedó, 2008a, p. 11). En estos debates sobre la cocina costarricense, el mayor espacio está acordado a la discusión de los aportes europeos y la herencia autóctona, sobre todo la mesoamericana. ${ }^{6}$ Esta última se manifiesta en los alimentos básicos como el maíz y los frijoles, en comidas a base de maíz, como las tortillas, los tamales o los atoles, así como en ciertas técnicas de preparación, como el uso del comal o del metate 7 (Álvarez, 2005, pp. 23-25; González, 2001, pp. 22-25; Ross, 1986, pp. 15-20; Ross, 2001, pp. 33-44). El vínculo entre la cocina nacional y las culturas autóctonas mesoamericanas frecuentemente está demostrado recurriendo a la cultura culinaria de los pobladores de la Gran Nicoya, particularmente a la cultura chorotega, y por la aclaración de las semejanzas entre esta y la cultura azteca. Un ejemplo de esto es la siguiente descripción de los tamales tomada del libro Entre el comal y la olla de Marjorie Ross González (2001):

Los chorotegas aliñaban los tamales con semillas de ayote molidas y otros condimentos, lo mismo que con carnes - de xulo o perro mudo, chompipe, venado, tepeizcuintle, etc. - con tomate, miel de abeja o caracoles. Esa salsa, de tomate, pepitas de ayote y chile rojo, se utilizaba también profusamente en la comida azteca. En México, y en la Meseta Central costarricense, esta salsa ha conservado su pureza, y se sigue usando lo mismo que entonces, llamada con el mismo nombre náhuatl: pipián. (p. 41). ${ }^{8}$

La cocina nacional costarricense descrita en estos discursos está presentada como parecida a las culturas culinarias de los demás países centroamericanos y como perteneciente al contexto cultural mesoamericano. Esta pertenencia cultural también se manifiesta en la enumeración de los platos puestos de relieve como ejemplares de la cocina criolla costarricense: entre estos se encuentra el gallo pinto, la olla de carne, los tamales, las chorreadas, el arroz con leche, los picadillos y las tortillas (Álvarez, 2005, p. 45; Ross, 2001, pp. 73-75; Sedó, 2008a, p. 12). La mayoría de estas comidas, aunque presentan particularidades en la forma de preparación y combinación de ingredientes y por ello típicas del país costarricense, o sea de la zona del Valle Central, ${ }^{9}$ como señalan las autoras Milena Cerdas Núñez y Patricia Sedó Masís (2008), son evidencia de las influencias culturales que comparte la cocina nacional costarricense con las demás cocinas nacionales de la región centroamericana (p. 19; Sedó, 2008a, p. 12). 
El concepto de la cocina costarricense refleja así el nuevo concepto de la identidad costarricense, como culturalmente heterogénea y oriunda de diferentes raíces culturales. Esta importancia dada a la valoración de la heterogeneidad cultural y regional también se nota en la particularidad de los discursos de la cocina nacional costarricense.

A pesar de la identificación de unos platos nacionales y la predominancia de las recetas de la cocina vallecentralista, a diferencia de la estrategia común en el proceso de construcción de cocinas nacionales anteriormente mencionado y en congruencia con los discursos actuales de nacionalidad costarricense, las culturas culinarias regionales no son silenciadas. Por lo contrario, todos los autores convienen en que hay que diferenciar al menos tres cocinas regionales: la cocina del Valle Central, la cocina guanacasteca y la cocina afrolimonense (Chang, 2001, p. 123). En vez de callar las diferencias intranacionales, estas diferencias son expuestas y valoradas. Aquí, con la exclusión de los guanacastecos como "otros internos" de fondo (Molina, 2008, pp.19-22), me concentraré en la descripción de la cocina regional de Guanacaste en estos debates y en el rol de esta cocina como marcador de identidad.

\section{LA COCINA GUANACASTECA EN LOS DISCURSOS DE LA COCINA NACIONAL}

Por ser la región en que a partir del siglo XIII se asentaron los Chorotega y los Nicarao, grupos autóctonos oriundos del sur de México (González, 2001, p. 24; Ross, 2001, pp. 35-36), en los discursos actuales de la cocina nacional costarricense, la provincia de Guanacaste es definida como "exponente de Mesoamérica en Costa Rica" (Chang, 2001, p. 124), y su cultura culinaria es calificada como cultura del maíz, como la cocina regional más influenciada por la herencia mesoamericana (Álvarez, 2005, p. 15; Chang, 2001, pp. 124-125; González, 2001, p. 22). La pertenencia de Guanacaste a la cultura mesoamericana no solamente está hecha explícita por medio de las descripciones, sino se manifiesta en la selección de platos y bebidas considerados típicos de esta cocina regional. La figura 1, que muestra las comidas y bebidas guanacastecas mencionadas por las autoras Marjorie Ross González (2001), Patricia Sedó Masís (2008b), Giselle Chang Vargas (2001) y Yanori Álvarez Masís (2005) en sus descripciones de la cocina nacional costarricense, da una impresión de esto.

En las descripciones, las preparaciones a base de maíz presentan más de la mitad de las comidas y bebidas mencionadas. Además, se encuentran otros platos que son ampliamente percibidos como de herencia autóctona, entre ellos la carne en vaho, ${ }^{10}$ mencionada por las cuatro autoras, o la bebida coyol. 


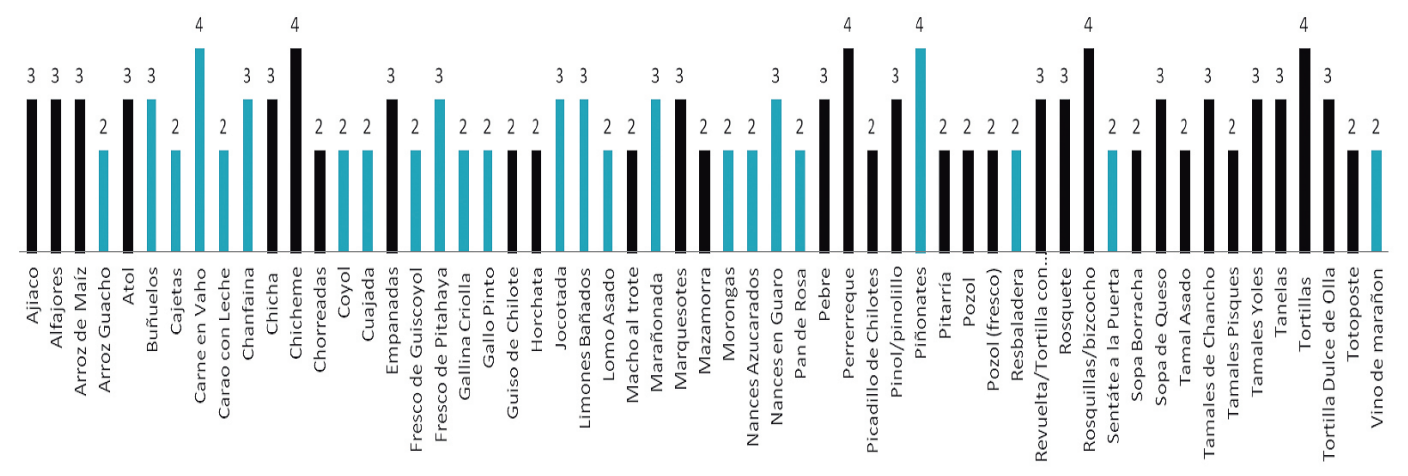

Figura 1. Comidas y bebidas guanacastecas.

Nota: Enumeraciones múltiples; comidas y bebidas a base de maíz marcadas en negro.

Fuente: Elaboración propia, con base en (Álvarez, 2005; Chang, 2001; Ross, 2001; Sedó, 2008b).

En los discursos de la cocina nacional entonces se reproduce la imagen de la cocina y cultura guanacasteca como mesoamericana. En vez de solamente demarcar la particularidad de esta cultura culinaria y región, el énfasis en la herencia autóctona de Guanacaste, como señalé en la sección anterior, también ayuda a ubicar a la cultura culinaria nacional en el contexto cultural mesoamericano. ${ }^{11}$ La importancia otorgada a la provincia guanacasteca para la cocina nacional quedó en evidencia todavía más claramente en mis entrevistas con costarricenses que viven fuera de Guanacaste, y sobre todo entre personas jóvenes, quienes percibieron a esta provincia como cuna de la cultura culinaria costarricense. Ale ${ }^{12}$ y Andrés, estudiantes en la ciudad de Heredia en el Valle Central, articularon esta opinión:

Ale: De hecho, mucha comida típica es de Guanacaste. Yo siempre he pensado que si Guanacaste no fuera anexado a Costa Rica, Costa Rica no tendría cultura.

Andrés: Porque toda la cultura que nosotros tenemos es de Guanacaste.

Ale: Es de Guanacaste. (Ale y Andrés, comunicación personal, diciembre, 2010)..$^{13}$

Esta valoración de la cultura autóctona mesoamericana y la cocina guanacasteca en los discursos de la cocina nacional costarricense significa un cambio en la percepción de la provincia de Guanacaste a nivel nacional: de una provincia marginada y entendida como culturalmente distinta de la nación costarricense a la cuna de la cultura culinaria costarricense.

En lo que sigue, presentaré la discusión de los discursos de la cocina nacional y del concepto de la cocina guanacasteca en Santa Cruz. Me enfocaré en la importancia de la cocina guanacasteca como marcador de identidad regional y el impacto de los discursos actuales sobre la cocina nacional costarricense en esta. 


\section{LA IMAGEN LOCAL DE LA COCINA GUANACASTECA}

En las entrevistas con mis informantes santacruceños, se perfiló una fuerte identificación de ellos con la cocina local. Se refirieron a esta cocina usando el término "cocina criolla", explicando la palabra criollo de la manera siguiente: "Criollo, muy lo nuestro, muy lo nuestro. Lo que se prepara en casa" (Mariana, comunicación personal, julio, 2011). Aunque al utilizar el término criollo Mariana, ama de casa y cocinera en las fiestas cívicas, no pensaba en las múltiples influencias en la cultura culinaria guanacasteca, ella, a lo largo de la entrevista, puso de relieve la herencia autóctona mesoamericana, superponiendo esta a los aportes españoles: "Pienso que más indígenas que españoles, ¿verdad? Porque los indígenas trabajaban el maíz, ¿verdad? Preparaban las comidas de maíz. Pienso más indígena que español" (Mariana, comunicación personal, 2011). Esta importancia dada al aspecto de la herencia mesoamericana de la cultura e identidad guanacastecas y al maíz como grano básico, se notó tanto en la discusión local como en la oferta de platos típicos preparados para las celebraciones de la Anexión de Guanacaste, así como también en las actividades relacionadas con estas festividades, entre ellas la elección de la "reina del maíz" en las escuelas, y en la enumeración de platos considerados pertenecientes a la cocina guanacasteca, presentada en la figura $2 .{ }^{14}$

Una comparación de esta imagen local de la cocina, cultura e identidad guanacastecas y la imagen expresada a nivel nacional, en los discursos de la cocina nacional costarricense, marca las semejanzas entre las dos imágenes, y sobre todo la conformidad de ambas respecto a la relevancia del concepto de la cultura del maíz. A primera vista entonces, la imagen local de la cultura e identidad guanacastecas apoya la imagen nacional tanto de esta cultura, identidad y cocina regionales, como también de la identidad y cocina nacionales. A pesar de las semejanzas, sin embargo, la imagen de la cultura del maíz que caracteriza a los guanacastecos, como mostraré en adelante, no se puede entender como un concepto de identidad originado por instituciones dominantes con que los actores sociales locales se identifican, por lo que no se puede aplicar el concepto de identidad legitimadora de Castells (2004, p. 8).

\section{LA CULTURA DEL MAÍZ COMO BASE DE LA IDENTIDAD DE RESISTENCIA GUANACASTECA}

Discutiendo la construcción de una cocina nacional costarricense, mis informantes santacruceños constituyeron la propia identidad en contraste con la cultura 


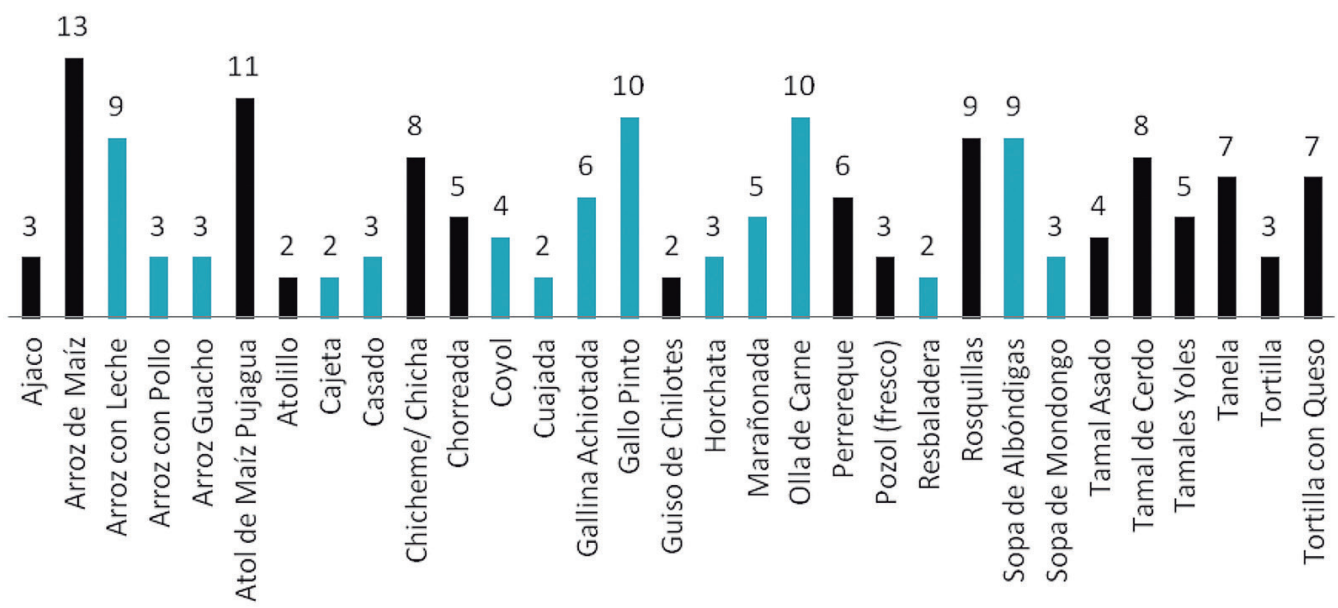

Figura 2. Comidas y bebidas guanacastecas mencionadas por mis informantes santacruceños. Nota: Resultados de 15 Free Listings; comidas y bebidas a base de maíz marcadas en negro. Fuente: Elaboración propia con base en Free-Listing.

vallecentralista, o sea con un "otro costarricense". Recurrieron a la imagen de la cultura del maíz para expresar la singularidad de la propia cocina y negar la existencia de una cocina nacional. En vez de percibir a la propia cocina como la cocina más caracterizada por las influencias mesoamericanas en Costa Rica, entendieron la herencia autóctona mesoamericana como limitada a la cultura culinaria guanacasteca. Este punto de vista se revela en la expresión de don Albert, profesor pensionado del colegio de Santa Cruz, quien, hablando de la centralidad del maíz en la cultura guanacasteca, dijo:

Hacen una cantidad de alimentos del maíz. Eso es propio de los indígenas, de los originarios, autóctonos. Ellos [los costarricenses] no tienen esta cultura. Ellos no tienen esta cultura, la están agarrando de nosotros, muchas cosas han agarrado de nosotros, del maíz. El maíz es de nosotros. (Albert, comunicación personal, julio, 2011).

Víctor, abogado y aficionado de la historia precolombina de Costa Rica, expresó una opinión parecida al rechazar la idea de la existencia de una cocina nacional costarricense:

Ellos cogieron 'cocina costarricense', pero tienen que distinguir dos. La cocina guanacasteca y la cocina costarricense. Yo no digo que no hayan cocinado, ellos [los costarricenses] tienen que haber cocinado, pero ellos son muy distintos. Son muy distintos inclusive como, se le vuelvo a decir, ellos tienen como grano fundamental el trigo. Nosotros, el maíz. Nosotros, como Nicaragua, como México, como Guatemala, el maíz. Ellos no. Ellos aprendieron al 
maíz, aprendieron al maíz, porque no era un grano de ellos, lo han aprendido.

(Víctor, comunicación personal, julio, 2011).

Otros informantes, aunque a veces no se refirieron tan explícitamente a la herencia autóctona mesoamericana, consideraron la presencia en la vida cotidiana de platos y bebidas a base de maíz como la diferencia más significativa entre la cultura culinaria guanacasteca y la costarricense.

La discusión local de la cocina nacional costarricense da cuenta de la importancia otorgada a la propia cultura culinaria como marcador de identidad regional. En esta discusión, mis informantes reclamaron la herencia mesoamericana como propia de Guanacaste, basando sus reclamaciones en la historia precolombina de esta provincia y en los discursos históricos de identidad nacional, caracterizando a los costarricenses como europeos - como cultura del trigo-, y a la herencia autóctona mesoamericana como limitada a Guanacaste. En vez de calificar a la propia cultura y región como cuna de la tradición culinaria nacional, la imagen de la propia identidad y cultura como cultura del maíz constituida en el transcurso de la discusión local sobre la cocina nacional costarricense, sirve como marcador de la identidad guanacasteca y la separa de la identidad nacional. La histórica separación entre la cultura guanacasteca y la cultura costarricense se mantiene. En este contexto, sin embargo, no son los guanacastecos excluidos de los discursos de nacionalidad costarricense; son mis informantes guanacastecos los interesados en sostener la separación. A la vez de ubicar a Guanacaste en el contexto cultural mesoamericano y confirmar la pertenencia cultural de Guanacaste a Mesoamérica, la insistencia en la propiedad exclusiva de la herencia autóctona mesoamericana excluye a los costarricenses de este contexto. Por lo tanto, utilizando el concepto de Manuel Castells, la identidad guanacasteca expresada a nivel local como cultura del maíz puede entenderse como identidad de resistencia. Los actores sociales marginados se refieren a una identidad histórica, mediante la cual excluyen a los que antes los habían excluido (Castells, 2004, p. 9), o, como en este caso, están tratando de excluirlos.

Como ya se indicó en los argumentos anteriormente citados, mis informantes, realzando la unicidad de la cocina guanacasteca a nivel nacional, hasta insinuaron la ausencia de una cocina digna de mención en el Valle Central o Costa Rica. Para Ana, vendedora de ropa, y su amiga Cinthia, cocinera en una soda, esta ausencia explica el interés de los turistas vallecentralistas en conocer y comer los platos guanacastecos:

Ana: Como las playas. De allá [del Valle Central], de todo lado vienen a buscar playas aquí en Guanacaste. Así es con todo. Yo no iría a San José para comerme una comida de allá, prefiero lo que hay aquí. 
Cinthia: Sí, porque ahí, se comen arroz y frijoles, nada más. (Ana y Cinthia, comunicación personal, julio, 2011).

En esta cita, Ana menciona las playas guanacastecas, y así coloca la cocina regional en la serie de elementos culturales y naturales que mis informantes santacruceños consideraron como propios de Guanacaste y como apropiados y explotados por el Estado costarricense, sobre todo con fines turísticos. ${ }^{15}$ Junto con la conciencia del valor de la propia cultura culinaria, como se puede ver en las expresiones citadas, surge la ansiedad por la apropiación en favor del patrimonio de Costa Rica. Por otro lado, también surge el miedo de perderla por el abandono. Es en este contexto que ocurre un cambio en la percepción de la cultura nicaragüense y de la transmigración nicaragüense.

En el apartado siguiente me ocuparé de la relación entre Nicaragua y Guanacaste. Mostraré cómo la construcción relacional de la identidad guanacasteca a distinción de la nicaragüense se expresa en el debate de la cocina regional, y cómo la construcción de una identidad guanacasteca en contraste con la costarricense impacta en esta imagen y en la percepción de la transmigración nicaragüense.

\section{LA COCINA GUANACASTECA Y LA DISTINCIÓN DE NICARAGUA}

Ante el desprecio histórico de la población nicaragüense y de Guanacaste como prolongación de Nicaragua por parte de la población costarricense, así como la pronunciación recurrente de derechos sobre la provincia de Guanacaste por parte del Gobierno nicaragüense, mis informantes santacruceños dieron mucha importancia a la distinción de su propia cultura culinaria y la nicaragüense. Esto se notó en la discusión local del concepto de la cocina guanacasteca que es percibida como bastante diferente a la nicaragüense. ${ }^{16}$ Por ello, la percepción local de algunos platos como nicaragüenses incidió en la discusión de la representación de la cocina guanacasteca en los discursos y los libros de cocina costarricense. Entre estos, la carne en vaho, más que cualquier otro plato mencionado en las secciones que tratan la cocina guanacasteca, promovió protesta entre mis informantes. Así, al hojear el libro La cocina tradicional costarricense 1: Guanacaste y Región Central de Puntarenas publicado por Yanori Álvarez Masís en 2005, ${ }^{17}$ Elena y Jessica negaron rotundamente la pertenencia de esta receta a la cocina guanacasteca. Después de haber explicado cómo se prepara esta comida, Jessica, ama de casa que es casada con un nicaragüense, manifestó: "La carne en vaho para el nicaragüense es como el arroz de maíz para el guanacasteco. Es un plato nicaragüense, no es de aquí" (Jessica, comunicación personal, julio, 2011), a lo que Elena añadió: "En Guanacaste no 
se prepara. Quién sabe por qué lo pusieron" (Elena, comunicación personal, julio, 2011). Elena y Jessica tomaron el hecho de que este plato característico de la cocina nicaragüense era clasificado como guanacasteco por una falta de consideración y de conocimiento de la cocina guanacasteca por parte de los autores. Este debate de la carne en vaho ilustra la manera en que se construye y expresa la identidad regional guanacasteca en la discusión de la cocina regional: Al rechazar la pertenencia a la cocina guanacasteca de platos considerados como nicaragüenses, a la vez que esta es presentada como "no nicaragüense", la imagen externa de la identidad guanacasteca como nicaragüense también es rechazada. En la discusión del concepto de la cocina guanacasteca entonces se manifiesta la construcción de la propia identidad en relación y como diferente a un "otro", señalado entre algunos autores por Cornell y Hartmann (2007, p. 84), y en este caso un "otro nicaragüense".

La importancia de construir la propia identidad como no nicaragüense impactó en la percepción de las influencias de la transmigración nicaragüense en la cultura culinaria local. Así, Paulina, cocinera en las fiestas cívicas y ama de casa, quien tiene unos amigos nicaragüenses con quienes frecuentemente comparte comidas, insistió: "No, no, jamás, en nada, en nada cambian lo que uno sabe hacer a lo que ellos hacen" (Paulina, comunicación personal, julio, 2011). Como Paulina, la mayoría de mis informantes consideraron el impacto de la transmigración nicaragüense en los propios hábitos alimenticios como insignificante y refutaron la posibilidad de adoptar los platos o los hábitos alimenticios nicaragüenses. A pesar de que muchos mantienen relaciones amistosas o familiares con transmigrantes nicaragüenses, dieron importancia a mantener la forma de preparación que calificaron como propia y guanacasteca.

\section{LA AUTOIMAGEN COMO CULTURA DEL MAÍZ Y EL CAMBIO EN LA PERCEPCIÓN DE NICARAGUA}

Como describí en la sección anterior, en los discursos locales de la identidad y cocina guanacastecas, la nación y la cultura nicaragüienses desempeñan el rol de un "otro", la construcción de la identidad guanacasteca resulta un proceso de distinción de lo nicaragüense. En el momento de lamentar el abandono progresivo de la cultura culinaria guanacasteca, sin embargo, sobre todo mis informantes que se interesaron mucho en la cultura precolombina costarricense, expresaron otra manera de ver la cultura nicaragüense. Es interesante aquí citar la opinión de don Mario, escultor y artesano, en esta situación sobre la carne en vaho, por ser un ejemplo de la construcción relacional de la cultura e identidad guanacastecas: 
Mario: ¿Ha visto una comida que hacen en Nicaragua con piedras, piedras, que es muy indígena? ¿La carne en vaho?

Mona: Mhm.

Mario: Van a poner la carne en una parte, con las piedras la tapan, después ponen las verduras, la verdura entre más suave, más arriba, para que no se, se deshaga. Entonces ese tipo, lo revuelven. Esas piedras son muy indígenas, muy indígenas. Aquí, los indígenas lo hacían, pero después se perdió esta costumbre. La forma de la cocina nuestra, lo que es la preparación del alimento, cambió totalmente. (Mario, comunicación personal, junio, 2011).

Esta cita da cuenta de la manera en que diferentes detalles de los platos están puestos de relieve en la discusión de la cocina regional, dependiendo del contexto del debate, así como del aspecto de la propia cultura e identidad que la persona intenta realzar.

La carne en vaho, cuya pertenencia a la cocina local generalmente era negada por mis informantes por ser un plato nicaragüense, para don Mario es más que un plato típico de la cocina nicaragüense contemporánea. Criticando la pérdida de la cultura culinaria local, don Mario puso de relieve la herencia autóctona que, como mencioné anteriormente, es ampliamente atribuida a este plato en el discurso público, ${ }^{18}$ y lo tomó como ejemplo de una parte de la herencia autóctona mesoamericana que se perdió en Guanacaste, mientras que se ha preservado en Nicaragua. Como don Mario en la discusión de este plato, cuando lamentaron la pérdida de la propia cultura culinaria, mis informantes santacruceños vieron la cultura nicaragüense como mesoamericana en primer lugar. Desaprobando el abandono de la propia cultura y lo que él entiende como un esfuerzo entre los guanacastecos por adoptar un estilo de vida parecido al de la población del Valle Central, Víctor reprobó el desprecio guanacasteco hacia la población nicaragüense, lo que interpreta como extensión de la discriminación histórica de la población guanacasteca en Costa Rica:

A los guanacastecos los han hecho creer que son nicas, entonces, ellos se sienten feísimo, porque Nicaragua era, el tico ${ }^{19}$ la tiene un alto desprecio, entonces el guanacasteco, por eso digo que el guanacasteco quiere ser como el tico, porque él también desprecia al nicaragüense, al nica, pero es de ahí viene, a diferencia del tico, él sí viene del nicaragüense, o sea, él sí viene del mexicano, el tico no. (Víctor, comunicación personal, julio, 2011).

Aunque ubica el origen de la población guanacasteca regionalmente en Nicaragua, Víctor no entiende a los guanacastecos como nicaragüenses, sino subraya el origen mexicano, mejor dicho, el origen autóctono mesoamericano que comparten los guanacastecos y los nicaragüienses y que, según su opinión, falta a los costarricenses del Valle Central. 
Este modo de ver la cultura nicaragüense como mesoamericana en primer lugar, también promovió un cambio en la manera de juzgar a los transmigrantes nicaragüenses y su impacto en los hábitos alimenticios locales. Don Albert expresando su preocupación por el abandono de la cultura culinaria local, puso en contraste los impactos nicaragüenses y costarricenses diciendo:

\footnotetext{
No tiene tanto impacto, porque los nicaragüenses que vienen, vienen a aumentar, a aumentarnos a nosotros que somos de la misma raíz que ellos, ya... Los ticos que están viniendo, vienen a hacer cambiar nuestras costumbres, nuestra cultura. (Albert, comunicación personal, julio, 2011).
}

A pesar de que él tampoco entiende a los guanacastecos como nicaragüenses, por el hecho de que comparten la misma raíz autóctona juzgó la transmigración desde Nicaragua como posible manera de fomentar los esfuerzos para mantener la propia cultura culinaria regional.

\section{CONCLUSIÓN}

En el contexto de la transnacionalización del consumo y de la construcción y tematización de una cocina nacional costarricense, crece a nivel local la conciencia por el valor de la propia cultura culinaria guanacasteca y esta gana importancia como marcador de la identidad regional. Mis informantes santacruceños se concienciaron del peligro de perder la propia cocina, sea por su apropiación y transformación en una cultura culinaria nacional costarricense, o por su caída en desuso. En la discusión local de la construcción de la cocina nacional costarricense se nota el impacto de los discursos históricos de nacionalidad y la marginación de los guanacastecos. La caracterización histórica de Guanacaste como zona influida por los rasgos culturales autóctonos mesoamericanos, actualmente forma la base de una identidad guanacasteca que se puede entender como identidad de resistencia. A pesar de que la imagen expresada a nivel local se parece a la imagen presente en los discursos académicos y en las adscripciones nacionales de la cocina y cultura guanacastecas, en la discusión local de la cocina nacional realza la unicidad de la cocina, cultura e identidad regional y la diferencia de la cocina, cultura e identidad nacional. La reclamación de la herencia autóctona mesoamericana en la discusión local de la cocina nacional, a la vez de ubicar la cultura guanacasteca en el contexto cultural mesoamericano, confirmar su pertenencia a Mesoamérica y separarla de la nación costarricense, también promueve una percepción de la cultura nicaragüense y de los nicaragüenses como mesoamericanos en primer lugar. La primacía dada al elemento cultural, la cultura del maíz como base de identidad, presenta la 
posibilidad de renegociar la imagen de la transmigración nicaragüense y la relación guanacasteca con Nicaragua, por poner la pertenencia al gran contexto cultural mesoamericano ante la pertenencia nacional e inclusive regional.

\section{NOTAS}

* Deseo expresar mis agradecimientos a la Escuela de Antropología de la Universidad de Costa Rica; al DAAD (Servicio Alemán de Intercambio Académico), por el apoyo financiero de mi trabajo de campo; a María Laura Vargas Arias y a José Pablo Madrigal Alemán. Finalmente, no quiero dejar sin mención mi agradecimiento por el apoyo constante que me brindó el Dr. Rolando Quesada Sancho (†) durante mi estancia en Costa Rica de setiembre 2010 a agosto 2011 .

1 El enfoque principal de estos trabajos es en las cocinas regionales de Limón (Chang, 1984, p. 46; Pardo, 2003, p. 21; Ross, 2002, pp. 12-13) y Guanacaste (García y García, 1981, Epílogo).

2 Entre los trabajos publicados destacan los estudios de Patricia Vega Jiménez (1991), quien tematiza la diversificación de patrones de consumo en el siglo XIX (pp. 53-87) y describe las historias locales del café y del gallo pinto y su transformación en símbolos de la identidad nacional costarricense (Vega, 2004, 2012, pp. 223-240). También hay que mencionar el trabajo de Iván Molina Jiménez (2008) en el que subraya la importancia de los hábitos de consumo como marcadores de identidades sociales en el siglo XX (pp. 93-99).

3 Esta preocupación por la cocina nacional se nota en el número de proyectos originados en los últimos años con el fin de rescatar esta cocina. Entre estos proyectos se encuentran los certámenes de "Comidas y Bebidas Típicas", que a partir de 2001 son efectuados anualmente por el Ministerio de Cultura y Juventud; el proyecto Trabajo Comunal Universitario de la Universidad de Costa Rica "Rescate de la cocina criolla con la participación de personas adultas mayores", iniciado por Patricia Sedó Masís en 2003; los talleres de gastronomía tradicional del Museo de Cultura Popular, y los estudios de Marjorie Ross (Ross, 1986, 2001, 2002, 2008, pp. 4-31).

4 Por razones de espacio, en este artículo me enfoco en el concepto de la "cultura del maíz", que es un aspecto central de la imagen local, así como de la imagen externa de la cultura guanacasteca y que es sumamente importante considerar por el cambio en el valor otorgado a la cultura autóctona mesoamericana a nivel nacional en los discursos de la identidad y de la cocina nacional costarricense, también por ser el aspecto a lo que mis informantes santacruceños 
concedieron una importancia especial en los debates. Esto no quiere decir que veo la cultura del maíz como base única de la identidad guanacasteca. Otro aspecto igualmente importante, que forma base tanto de la imagen externa como de la imagen local de la cultura e identidad guanacastecas, es el concepto de la "cultura sabanera" (Cabrera, 1989, p. 13).

Me enfoco en los trabajos de estas cuatro autoras, por ser las investigadoras que actualmente trabajan y publican más sobre el tema del rescate de la cocina nacional costarricense, y desde diferentes perspectivas académicas. Patricia Sedó Masís, directora de la Escuela de Nutrición de la Universidad de Costa Rica e iniciadora del proyecto de Trabajo Comunal Universitario "Rescate de la cocina criolla con la participación de personas adultas mayores", en cuyo transcurso se hicieron varias publicaciones (Sedó, 2008a, p. 11); Giselle Chang Vargas, antropóloga de la Escuela de Antropología, quien colaboró en la publicación del libro Nuestras comidas (Chang, 2001), elaborando los capítulos sobre la cocina costarricense, mientras que Fernando González Vásquez y Aida Blanco Vargas trataron las influencias precolombinas en la alimentación costarricense (Blanco, 2001, pp. 19-21; González, 2001, pp. 22-27); Yanori Álvarez Masís, historiadora, quien compuso las recetas en los libros publicados a continuación de los certámenes de "Comidas y Bebidas Típicas" realizados por el Ministerio de Cultura y Juventud, y Marjorie Ross, pionera en la investigación de la cocina costarricense. A pesar de que esta es una reseña pequeña de las publicaciones sobre el tema, considero los trabajos de estas autoras como los más importantes, por ser las fuentes de referencia para los demás autores, y en esa medida los más difundidos, y por ello, los más leídos y discutidos por mis informantes.

La importancia concedida a estas dos influencias se nota en el espacio dedicado a la descripción de los aportes a la cocina costarricense en las publicaciones académicas. En su libro Entre el comal y la olla, Marjorie Ross González (2001) identifica la cultura culinaria española, la prehispánica y la africana como influencias centrales en la cocina costarricense, tratándolas por separado y detalladamente (pp. 32-68). Las demás influencias las discute con menos detalle (pp. 68-72). Mientras que los otros autores se enfocan en la herencia autóctona y la europea. En el libro Nuestras comidas (2001) hay dos capítulos que tratan las influencias autóctonas en la cocina costarricense (Blanco, 2001, pp. 19-21; González, 2001, pp. 22-27), y en el capítulo sobre los aportes foráneos, Giselle Chang Vargas (2001) se centra en los aportes europeos y solamente menciona algunas influencias de la cultura afrocaribeña, china y norteamericana (pp. 63-68). De la misma manera, Yanori Álvarez Masís (2005) dedica un capítulo a la discusión de la gastronomía autóctona y los productos autóctonos (pp. 21-36) y a los productos foráneos, introducidos por los europeos (pp. 37-41). mesoamericana como suramericana, en la cocina costarricense, un hecho que no es negado 
en la discusión de las influencias en la cocina costarricense. Por lo general, sin embargo, se da mucho menos consideración a las influencias precolombinas suramericanas, las cuales son entendidas como contribuciones menos importantes (Álvarez, 2005, p. 24).

8 Véase también (Ross, 1986, pp. 17-18). Otras autoras, entre ellas Milena Cerdas Núñez y Patricia Sedó Masís (2008), igualmente mencionan esta relación entre la cultura chorotega y la cultura culinaria azteca, y así vinculan la cultura culinaria costarricense con las culturas mesoamericanas, subrayando así su historia milenaria (p. 27).

9 La predominancia de la cocina vallecentralista se nota tanto en los nombres de los platos como en las mismas recetas publicadas, en las que se presenta la forma de preparación y combinación de alimentos que es característica de la cocina vallecentralista.

10 Marjorie Ross de Cerdas (2002) define la carne en vaho como plato de herencia africana (p. 76). A pesar de ello, esta comida es ampliamente tomada por un plato autóctono mesoamericano en los discursos públicos y privados. Esta noción también se encuentra en las publicaciones didácticas, como por ejemplo en el libro Al reencuentro de los ancestros, en que la autora Anayensy Herrera (2007) menciona la carne en vaho como ejemplo de un plato de herencia autóctona (p. 31).

11 Diciendo eso, no quiero mantener que no había contacto cultural entre la zona vallecentralista y la guanacasteca o que no había influencia autóctona mesoamericana en la cultura culinaria del Valle Central - Roberto Cabrera Padilla (2007), a pesar de subrayar la marginación histórica de la provincia guanacasteca y las diferencias culturales marcadas entre esta y la zona de la Meseta Central costarricense, también indica el papel de Guanacaste como "abastecedora de fuerza de trabajo migratoria" (p. 305) - , lo que quiero manifestar es que por la referencia común en los discursos de cocina nacional al área de la Gran Nicoya y a la cultura chorotega, fuertemente asociada con esta región, se acuerda una posición central a la provincia guanacasteca en los discursos académicos, que armoniza con la relevancia atribuida a esta región en los discursos públicos y privados y tal vez la fomenta.

12 Por razones de protección de datos personales de mis informantes, todos los nombres son ficticios.

13 En un artículo que trata la expresión de identidades culturales en las discusiones del plato nacional costarricense gallo pinto, Theresa Preston-Werner (2009) menciona esta misma percepción de Guanacaste como cuna de la cultura culinaria costarricense entre sus informantes en la zona Pacífico Sur (p. 20). 
14 Las enumeraciones también expresan la imagen de la cultura sabanera, con platos como el gallo pinto, la cuajada, el arroz guacho, la gallina achiotada o la sopa de albóndigas. Por razones de espacio, tengo que limitar mi discusión aquí a la expresión de la propia cultura e identidad como cultura del maíz.

15 Con respecto a la explotación turística de Guanacaste, queda por decir que fue el grupo de la "Casa guanacasteca", es decir, un grupo de guanacastecos que vivían en el Valle Central, quienes en los años treinta tomaron la iniciativa para promover el desarrollo turístico de esta región y que todavía en los años ochenta se consideraba a los proyectos turísticos, también a nivel local, como medio para combatir el subdesarrollo económico de la zona. Sin embargo, a partir de los años noventa se dieron cuenta de que ni la región ni la población local se beneficiaron de los megaproyectos (Arrieta y Rivera, 2009, pp. 143, 152-153). Frente a esta imposibilidad de beneficiarse del desarrollo turístico y ante la opinión comúnmente compartida de que en Costa Rica no hay atracciones ambientales y culturales como en Guanacaste, mis informantes expresaron sentimientos de explotación de la propia cultura y región. A pesar de que veían al Gobierno local como culpable de esta situación, también culparon al Gobierno nacional.

16 Con respecto a esto, quiero destacar que los transmigrantes nicaragüenses de Santa Cruz, algunos de ellos casados con mis informantes locales o amigos de ellos, compartían esta opinión. Por lo general, describieron la cocina nicaragüense como mucho más amplia y variada que la guanacasteca y al igual que mis informantes santacruceños, pusieron de relieve las diferentes formas de preparación de platos existentes en ambas cocinas. Por lo contrario, los transmigrantes nicaragüenses que entrevisté en el Valle Central consideraron ambas cocinas como parecidas y hasta iguales. Esta percepción diferente entre ambos grupos también indica la importancia de la distinción a nivel local, y la forma en que se utiliza la cocina para manifestar diferencias.

17 Este libro contiene una compilación de recetas que contribuyeron los participantes locales, es decir guanacastecos, al concurso de "Comidas y Bebidas Típicas de Guanacaste". Sin embargo, el hecho de que muy probablemente era una persona local quien contribuyó la receta de la carne en vaho como guanacasteca, no afectó la manera común de considerar la incorporación de este plato como decisión errónea.

18 En la discusión de la carne en vaho, don Mario se refiere a una forma de preparación de este plato que difiere de la que se encuentra en los estudios académicos, pero que apoya su punto de vista y su argumento. A nivel local, coexistieron estas dos opiniones sobre el modo en que se prepara esta receta. El debate da cuenta del uso selectivo de las imágenes y los aspectos de diferentes platos y de la importancia de las imágenes de la opinión pública. Se recurre a los diferentes 
aspectos de la herencia autóctona o la pertenencia a la cocina nicaragüense, mientras que no se toma en cuenta el aspecto de la herencia africana, presente en los discursos académicos.

19 Apodo para referirse a los costarricenses. Mis informantes santacruceños lo utilizaban para referirse a la población costarricense del Valle Central.

\section{REFERENCIAS}

Álvarez, Y. (Ed.). (2005). Cocina tradicional costarricense1.Guanacaste y Región Central de Puntarenas. Costa Rica: Ministerio de Cultura, Juventud y Deportes.

Appadurai, A. (2008). How to make a National Cuisine: Cookbooks in Contemporary India. En C. Counihan y P. van Esterik (Eds.). Food and Culture. A Reader (pp. 289-307). Londres: Routledge.

Arrieta, G. y Rivera, G. (2009). El desarrollo del turismo en Guanacaste: de la Asociación Bella Vista al Instituto Costarricense de Turismo. En G. Arrieta (Ed.). Guanacaste: Historia de la (Re)construcción de una región. 1850-2007 (pp. 139-156). Costa Rica: Alma Mater.

Ayora-Diaz, S. I. (2010). Regionalism and the Institution of the Yucatecan Gastronomic Field. Food, Culture and Society, 13(3), 397-420.

Barlösius, E. (1999). Soziologie des Essens: eine sozial- und kulturwissenschaftliche Einführung in die Ernährungsforschung. Múnich: Juventa.

Blanco, A. (2001). Alimentos vegetales precolombinos de Costa Rica. En G. Chang (Ed.). Nuestras comidas (pp. 19-21). Costa Rica: CECC.

Cabrera, R. (1989). Santa Cruz, Guanacaste. Una aproximación a la historia y la cultura populares. Costa Rica: Ediciones Guayacán.

Cabrera, R. (2007). Tierra y ganadería en Guanacaste. Costa Rica: Editorial Tecnológica de Costa Rica.

Castells, M. (2004). The Power of Identity. Oxford: Blackwell Publishing.

Cerdas, M. y Sedó, P. (2008). Rescate de preparaciones a base de maíz en Costa Rica: Una experiencia de trabajo comunitario con la participación de personas adultas mayores y estudiantes 
universitarios durante el periodo 2003-2007. Avances de seguridad alimentaria y nutricional. Recuperado de: http://revistasan.ucr.ac.cr/san/index.php/revistasan/article/view/12/

Chacón, A. (2000). La etnicidad negra e indígena y los mitos de la nacionalidad costarricense. Kipus, Revista Andina de Letras, (11), 81-91.

Chang, G. (1984). Remedios caseros y comidas tradicionales afrolimonenses. Costa Rica: Editorial Ministerio de Educación.

Chang, G. (Ed.). (2001). Nuestras comidas. Costa Rica: CECC.

Cornell, S. y Hartmann, D. (2007). Ethnicity and Race: Making Identities in a Changing World. Estados Unidos: Pine Forge Press.

García, G. y García, L. E. (1981). Comidas y bebidas típicas de Guanacaste. Costa Rica: Editorial Costa Rica.

González, F. (2001). La alimentación precolombina. En G. Chang (Ed.). Nuestras comidas (pp. 22-27). Costa Rica: CECC.

Herrera, A. (2007). Al reencuentro de los ancestros. Mwaing Daamalut. Kokapoijmi. Costa Rica: Editorial ICER.

Instituto Nacional de Estadística y Censos. (2011). Cuadro 3: Costa Rica: Población total por zona y sexo, según provincia, cantón y distrito. Recuperado de: http://www.inec.go.cr/

Leal, E. (1998). Santa Cruz: El paraje de Diría. Costa Rica: Master Litho.

Molina, I. (2008). Costarricense por dicha. Identidad nacional y cambio cultural en Costa Rica durante los siglos XIX y XX. Costa Rica: Editorial de la Universidad de Costa Rica.

Molina, I. y Palmer, S. (2009). Historia de Costa Rica. Breve, actualizada y con ilustraciones. Costa Rica: Editorial de la Universidad de Costa Rica.

Morales, L. C. (2009). Santa Cruz de Guanacaste. Cultura local, turismo y globalización. Revista de Ciencias Sociales, 1-2(123-124), 35-48. Recuperado de: http://www.redalyc.org/src/inicio/ ArtPdfRed.jsp?iCve $=15313756003 /$ 
Pardo, E. (2003). Limón y su cocina. Recetas de cocina recopiladas por la Dra. Elena Pardo C. Costa Rica: Editorial de la Universidad de Costa Rica.

Parkhurst, P. (2010). Culinary Nationalism, Gastronomics. The Journal of Food and Culture, 10(1), 102-109.

Preston-Werner, T. (2009). Gallo Pinto: Tradition, Memory, and Identity in Costa Rican Foodways. Journal of American Folklore, 122(483), 11-24.

Ross, M. (1986). Al calor del fogón: 500 años de cocina costarricense. Costa Rica: Cultur/Art.

Ross, M. (2001). Entre el comal y la olla. Fundamentos de gastronomía costarricense. Costa Rica: EUNED.

Ross, M. (2002). La magia de la cocina limonense: Rice and Beans y Calalú. Costa Rica: Editorial de la Universidad de Costa Rica.

Ross, M. (2008). Metáforas de la cocina: Mi viaje de descubrimiento por la cocina costarricense. Revista Herencia, 21(1), 4-31.

Sandoval, C. (2004). Threatening Others. Nicaraguans and the Formation of National Identities in Costa Rica. Estados Unidos: Ohio University Press.

Sedó, P. (Ed.). (2008a). Glosario de cocina popular costarricense. Descripción general de alimentos, equipos, utensilios, técnicas de preparación y frases populares. Costa Rica: Universidad de Costa Rica.

Sedó, P. (Ed.). (2008b). Comidas y tradiciones de Costa Rica [CD-ROM]. Costa Rica: Universidad de Costa Rica.

Sutton, D. (2001). Remembrance of Repasts: An Anthropology of Food and Memory. Nueva York. Berg.

Vega, P. (2004). Con sabor a tertulia: Historia del consumo del café en Costa Rica (1840-1949). Costa Rica: Editorial de la Universidad de Costa Rica.

Vega, P. (julio/diciembre, 1991). De la banca al sofá. La diversificación de los patrones de consumo en San José (1857-1861). Revista de Historia, (24), 53-87. 
Vega, P. (2012). El Gallo Pinto: Afro-Caribbean Rice and Beans Conquer the Costa Rican National Cuisine. Food, Culture and Society, 15(2), 223-240.

\section{ACERCA DEL AUTOR}

Mona Nikolić: Máster en Antropología, Instituto de Antropología, Freie Universität Berlin (Universidad Libre de Berlín); Doctorado en Antropología Cultural, LAI (Instituto de Estudios Latinoamericanos, Freie Universität Berlin); dirección postal (LAI): Rüdesheimerstr. 54-56, 14197 Berlin, Alemania; teléfono: +49 160 1611812.Correo electrónico: mona.nikolic@web.de 